\title{
4 Understanding unwanted sexual touching
}

\author{
A situational approach
}

\author{
Kari Stefansen
}

\section{Introduction}

Situations involving unwanted sexual touching are analysed in this chapter in an effort to enhance our understanding of the social dynamics of this particular form of invading behaviour against girls and young women. The analysis is grounded in a situational perspective (which I will expand on later) that draws on Collins's (2009) micro-sociological approach to the study of violence. On the background of that analysis, I will discuss some of the wider ramifications or cultural consequences of the phenomenon of unwanted touching, with a focus on the harm such behaviour causes at the collective level. The starting point for this discussion is the idea that unwanted sexual touching, like rape and other forms of sexual violence, represents both 'a personal and systemic attack' (Munro, 2010, p. 26). The relevance of an analysis of unwanted sexual touching in a book about rape is that such an analysis contributes to our understanding of the boundaries and harm of sexual violence - issues that are high on the agenda among numerous socio-legal studies on rape law (e.g. McGlynn \& Munro, 2010). It is important to explore the harm and boundaries of sexual violence more generally, however, and not exclusively from a penal perspective, where phenomena such as intent and culpability are often placed in the foreground. My interest in this chapter is instead to draw our attention to the social aspect of unwanted sexual touching, particularly the way it unfolds in different interactional settings. The analysis highlights how context shapes sexual behaviour, an issue that is understudied in relation to sexual violence (Khan, Hirsch, Wamboldt, \& Mellins, 2018).

The situations I explore involve acts that in common parlance are referred to as groping, fondling, feeling up and similar terms. These are forms of unwanted and unsettling sexualised touching that may happen everywhere - on the bus, at school, at work and during parties and other social events. Viewed from a penal or hierarchical perspective on sexual violence, such acts may represent 'minor events' (Smart, 1995, p. 222) compared to violent rape, but they are prevalent and part of the everyday sexism that many girls and women encounter and must handle. Nationally representative studies among youths in Norway (the empirical context of my analysis) indeed confirm that unwanted touching is 


\section{Kari Stefansen}

widespread in the Nordic context, despite increasing efforts in recent years to prevent sexual violence among the youth population (for example, see Skilbrei \& Stefansen, 2018). The lifetime prevalence rates for 18-19-year olds are around 25\% among girls and 6-7\% among boys (Mossige \& Stefansen, 2007, 2016); the annual rates are correspondingly high. In a study among 16-18-year olds, $21 \%$ of girls and $9 \%$ of boys reported having experienced unwanted sexual touching in the past 12 months (Bakken, 2017). The referred-to studies among older youths were conducted eight years apart but showed similar rates, thus indicating that unwanted sexual touching (and sexual violence in general) is stable and frequent among youths in Norway. The consistently higher numbers for girls serve as a reminder that sexual violence is highly gendered, even if it also affects boys.

The analysis in this chapter is restricted to girls' experiences of unwanted touching, for the simple reason that the empirical material I analyse contains too few descriptions from boys to allow for a meaningful exploration. I analyse descriptions of unwanted touching that happened to girls after the age of 13 and that involved boys or young men of the same age as the girl or a few years older. Hence, the focus of attention is youth-related incidents of unwanted sexual touching, not childhood sexual abuse. The descriptions were gathered as part of a large-scale survey study conducted among students in the final year of upper secondary school (18-19-year olds). The descriptions are short and typically comprise two or three sentences, which means that the data are 'thin' compared to other types of qualitative data (such as interviews or fieldwork) that yield more complex and 'thick' data on the object of inquiry.

Other researchers have used this type of data to gain knowledge about different aspects of sexual encounters and transgressions. Examples include gendered patterns in regretting consensual sex (Krange \& Pedersen, 1999), women's labelling of rape and sexual assault (Kahn, 2004; Kahn, Jackson, Kully, Badger, \& Halvorsen, 2003; Stefansen \& Smette, 2006) and gendered aspects of incapacitated sexual assault (Stefansen, Överlien, \& Frøyland, in preparation). These studies, much as I do in the current chapter, simultaneously acknowledge the limitations of this type of data and make the epistemological claim that short descriptions of sexual and sexualising encounters that offer only glimpses of social interactions and contexts nevertheless can provide possibilities for the theorisation of the phenomenon in question. The potential of short descriptions in this respect relates to the fact that they are gathered as part of large-scale and often representative surveys; thus, they likely capture close to the full range of experiences related to the phenomenon of interest. The underlying idea of the analysis in this chapter is that a careful empirical patterning of unwanted sexual touching can contribute to an understanding of the social and situational dynamics involved in producing such incidents, which in turn can further scholarly discussions on the boundaries of sexual violence and the cultural effect of minor transgressions. In this sense, I follow up on the call from Fileborn $(2016$, p. 7$)$ to reignite scholarly discussion on 'the broader spectrum of sexually violent and unwanted behaviours'. 
The starting point for my analysis is that unwanted touching needs to be unpacked before we can understand its social dynamics, which means taking into account that unwanted sexual touching is and does different things in different situations. In the current literature, unwanted sexual touching is often understood in terms of unwanted sexual attention or sexual harassment. Within this strand of research, the spatial dimension of such transgressions has been the most common subject of attention. Specialised studies in the literature have focussed on sexual harassment on the street (Vera-Gray, 2016), in bars and other social-drinking venues (Graham, Bernards, Abbey, Dumas, \& Wells, 2017; Kavanaugh, 2013; Tinkler, Becker, \& Clayton, 2018), in schools and university campuses (Gillander Gådin \& Stein, 2017; LeMaire, Oswald, \& Russell, 2016) and online (Megarry, 2014; Thompson, 2018). Very few researchers have looked into the relational aspect of unwanted sexual attention in combination with spatiality, i.e. the socio-spatial contexts of unwanted sexual touching. In the current chapter, I take such contexts to represent different situational circumstances for unwanted sexual touching. I situate my analysis within the scholarship on sexual violence, to be discussed next.

\section{Theorisations of sexual violence}

To explore unwanted sexual touching means to explore the boundaries of sexual violence (cf. Fileborn, 2016). But what counts as sexual violence? Two main approaches to this question are the 'conceptual' and 'cataloguing' approaches (Munro, 2010, p. 17). Rather than listing specific behaviours that constitute sexual violence, the focus of the conceptual approach, which guides my analysis, is on what acts of sexual violence harm (Skilbrei \& Stefansen, 2018). Stang Dahl (1994), for instance, defines sexual violence as acts that violate a person's 'gender freedom', i.e. the right to decide for oneself when and how to engage in sexual interactions and how far these interactions can go. Kelly articulates a similar position, seeing sexual violence as acts that take away someone's 'ability to control intimate contact' (1988, p. 41). Both conceptualisations depart from a normative theory of sexual integrity or self-determination and agency as that which is harmed or compromised by sexual attacks (and which legal regulations today aim to protect). The same is the case in Cahill's sexual-ethics perspective $(2014,2016)$. Cahill's theorisation (to which I will return shortly) is especially relevant for my purposes because it also offers conceptual tools that encompass the 'grey area' of sexual or sexualised encounters those encounters that represent neither sexual violence nor reciprocal or wanted interactions but are located somewhere between the two.

So far, I have dealt with theorisations of acts of sexual violence. To facilitate discussion on the wider ramifications of unwanted sexual touching, I will also draw on theorisations of the collective aspect of sexual violence. One idea is that sexual violence can be understood as compromising what Cornell (2007, p. 230) calls the 'imaginary domain', meaning 'the moral and psychic space we all need in order to come to terms with who we are as sexuate beings and to 


\section{Kari Stefansen}

have the chance to claim our own person as a sexuate being'. ${ }^{1}$ The implication, which I draw from Bjørnholt and Helseth's reading (2019) of Cornell (1995), is that sexual violence compromises women's imaginary domain through the gendered power structures such violence upholds. Their interpretation echoes Munro's point (2010, p. 26), mentioned earlier, that rape (and sexual violence in general) simultaneously represents an attack on the personal and the cultural/ systemic levels. The systemic dimension of sexual violence implies that sexual violence may cause harm that transcends the harm experienced by those who are directly affected. When I later discuss the concept of a gendered 'phenomenology of fear' (Cahill, 2001, p. 143), I will draw on this line of thought. Below I expand on the situational perspective that has guided the empirical analysis.

\section{Analytical approach: the situational perspective}

The analysis in this chapter draws inspiration from Collins's (2009) microsociological approach to the study of violence. Collins claims that in order to understand the dynamics of violence, researchers should not study violent individuals, but violent situations. As Collins argues, 'we [must] seek the contours of situations, which shape the emotions and acts of individuals who step inside them', which means to 'put the interaction in the center of analysis, not the individual, the social background, the culture or even the motivation: that is to say, look for the characteristics of violent situations' (p. 1). Thus, researchers must look for the situations that occur within forms of violence, and compare them. I aim to do this in my analysis by identifying and comparing the sociospatial contexts in which unwanted touching occurs. Socio-spatial contexts, then, are defined by their normal flow of meaning or underlying social contract. It makes a difference, for instance, if the touching has happened in a 'sexualised space' (Fileborn, 2016; Kavanaugh, 2013) or in a more 'neutral' zone, for example at school or work. Hence, the use of the situational perspective allows for sensitivity towards the fluidity of unwanted sexual touching. This is an important consideration, since situations involving unwanted touching may shift rapidly from something wanted to unwanted, and vice versa (Demant \& Heinskou, 2011). The same act of unwanted touching may also be fundamentally ambiguous - wanted and unwanted at the same time. It may, for instance, both ignite feelings of devaluation and fear and work as a confirmation of a girl's sexual attractiveness and social standing (Stefansen, Smette, \& Bossy, 2014).

With this background, I understand unwanted sexual touching as acts that can potentially disrupt some of the normal flow of meaning that takes place in a given situation. The focus of the analysis will be on how such disruptions happen or are actualised and how they can be understood in terms of sexual violence. To that end, I will apply Cahill's sexual-ethics framework (2014, 2016). Cahill argues that sexual situations can be differentiated according to the degree of agency and possibility to affect the situation that the interaction allows for those involved. She identifies two main situations: 
ethically acceptable sex (or 'just sex') and ethically problematic sex, or 'unjust sex'. In ethically acceptable sex, both parties have agency, meaning that they both have recognised will in the situation, while in ethically problematic sex, the agency of one person is compromised. Unethical sexual acts do not necessarily represent a total undermining of the victim's agency, however, as some unethical acts allow for some form of agency. In these cases, the act does not constitute sexual violence. I will discuss how the different situations in which unwanted touching occurs can be understood, in light of Cahill's conceptual tools.

In the next section, I turn to the empirical basis of my analysis. Collins (2009, p. 2) argues that to 'see the patterns of confrontation, tension and emotional flow, which are at the heart of the situation where violence is carried out', researchers need data that will capture the details of the situation, preferably via direct observation. Given that such observation is seldom possible, video, reconstructions or observations of violent events are valid options. My data are a form of observation - from the perspective of the affected girl. Because they lack depth and detail, the analysis is explorative rather than comprehensive. This means that I can only sketch out the contours of situations in which unwanted touching occurs and infer the meaning for those involved and the dynamics related to the disruptive act.

\section{Methods, data and categorisations}

The short written descriptions I analyse were gathered through a large-scale survey study conducted among students in their final year of upper secondary school, aged 18-19 years. A representative sample of 67 upper secondary schools across Norway were recruited. The sample of schools was provided by Statistics Norway following a two-stage sampling procedure. All eligible upper secondary schools were allocated to five geographical regions to ensure participation from the whole country and then stratified within each region into three categories: academic track only, vocational track only and combined. The participating schools were drawn according to strata size to ensure proportional allocation. All final-year students in each school were invited to participate. A total of 7,033 students accepted, giving a response rate of $77 \%$.

The participants answered a questionnaire about different types of victimisation, including sexual victimisation, broadly defined. The questionnaire was administered in the classroom and with a teacher present. The participants answered yes or no to a set of questions about unwanted touching, attempted rape and rape before and after the age of 13. Any participants who indicated at least one such experience were asked to describe in their own words what had happened and the people involved (without providing names) for the first and last incidents. This material consisted of approximately 1,000 short, written descriptions. Among these descriptions, 164 were relevant for the analysis presented in this chapter. Among these descriptions, 97 were related to assailants whom the girl had defined as either a friend or an acquaintance; 10 were related to a boyfriend and 57 to a stranger. 


\section{Kari Stefansen}

The aim of the analysis was to identify situations of unwanted touching. To that end, I first grouped the descriptions according to the girl's relation to the assailant: whether he was a friend or acquaintance, a boyfriend or a stranger. Within these categories of relations, I identified where and how the unwanted touching had occurred. Taken together, these elements provide insights into the different interactional dynamics of unwanted touching. The labelling of each type of unwanted sexual touching is intended to capture the meaning of the different acts and to also enable analysis of the fluidity of the phenomenon. The forms of unwanted touching from friends and acquaintances that I conceptualise in this chapter are also described in Stefansen et al. (2014).

\section{Situations involving friends/acquaintances and boyfriends}

Friends and acquaintances were the most frequently occurring type of relation in the material. One distinct type of unwanted sexual touching from friends and acquaintances happens in public or semi-public places with other youths present. I use the label performative touching for these instances because the phrase highlights the relationship between the act of unwanted touching and the flow of meaning in a given situation. I interpret the acts as representing a form of role-play related to heterosexual stereotypes.

The typical scenario for this type of performative touching is the public space of schoolyards or hallways in lower secondary school, and situations where a boy suddenly reaches out and touches a sexualised area of a girl's body, for instance her breasts or thighs. The quotes below are illustrative:

He touched my boobs in recess, which I didn't want.

A group of boys our age touched the girls in middle school against our will especially one person, who was a year older than us. He held us really hard while he touched us.

Fondling by people my age and maybe a bit older at a youth club.

A classmate touched my breasts, and it was pretty obvious: right in the middle of the school hall.

These acts may be understood as being directed towards an audience of other boys as much as towards the girl; hence, the interaction in the situation is more between the boys than between the particular boy and girl involved in the sexualtouching incident. On this premise, these acts can be understood as representing performances of a sexualised form of male aggressiveness that reproduce ideas about masculinity and gendered hierarchies (Lahelma, 2002; Robinson, 2005).

The data include descriptions of similar behaviours from friends and acquaintances at parties or clubs, i.e. in arenas associated with romantic or sexual initiatives. I see these advances as being different from performative touching. Because they happened in sexualised spaces, they have a more explorative quality. The typical 
scenario is of a boy reaching out and signalling interest but being rejected by a girl. The premise for this interpretation is that while the particular act is unwanted (and may come as a surprise to the girl), sexual or romantic advances are to be expected in these situations, and they therefore represent part of the normal flow of meaning or general social energy or 'vibe'. I label these acts explorative touching. The following quotes describe typical situations:

He made a pass at me; it wasn't much. He stopped right away when I told him off.

He touched my thighs and sat down next to me. Before he had a chance to embrace me, I stood up. I was with my friends the rest of the evening.

I was at a birthday party. We were alone outside, so he made a pass at me.

In a sense, this form of unwanted sexual touching resembles what Kavanaugh (2013) describes as transgressions that stem from 'competing definitions of the situation' (p. 26). The situations represent a form of 'scorned sexual advance' (p. 26) that follows from a boy's misinterpretation of a girl's behaviour as signalling openness to some kind of contact. Kavanaugh's description is perhaps too simplistic, however. The notion of explorative touching highlights how such advances, while out of sync with the person they are directed against, at the same time are spurred by and in sync with the flow of meaning and interaction that defines the situation.

But some of the descriptions from parties or clubs in my data challenge the interpretation of all acts of unwanted touching in sexualised spaces as being explorative or inviting. Some acts of unwanted touching in these spaces seem to be more impulsive and random, and they happen in situations with other people present, as the following quotes show:

I was on the dance floor at a club when a guy came up behind me and touched me. I pushed him away.

Nothing serious, but sometimes people pass you and touch you at parties and so on.

[I was] felt up at a club on the dance floor (my breasts, between the legs, and my hips) despite me saying no.

Kavanaugh (2013, p. 28) labels such acts of unwanted sexual contact as 'opportunistic predation', referring to the fact that the assailant takes advantage of a complex situation, typically a crowded dance floor. In these situations, unlike the situations he labels 'competing definitions', no prior personal interaction has taken place between victim and assailant. Hence, while people may acknowledge this form of unwanted touching as a possibility or risk, they are perplexing when they happen. One might wonder whether these incidents are performative, since they happen when other 


\section{Kari Stefansen}

people are present, but the fleeting and in-passing nature of the incidents suggests otherwise. As Kavanaugh (2013) has described, girls will often not know who the assailant was because the touching happened in a crowd, with the actual act hidden from view. Rather than being performative - a display of sexualised masculinity aimed at an audience - such incidents could be interpreted as spurred by (and with the potential of adding to) the sexualised atmosphere and liminal quality of a party or club. The situational backdrop in this case is hence the flow of meaning that defines such spaces, and not a prior exchange of signals between individuals.

While incidents of opportunistic predation are unwanted and in some cases frightening for the girl, they are different from a third form of unwanted touching that I label aggressive touching. These are acts where the boy takes advantage of a girl while she is sleeping or heavily intoxicated, or where the boy uses physical force or other forms of coercion and constraint, such as by locking her in a room or car. Incidents where the boy had followed the girl - i.e. persistently stalked her - for a whole evening are also included in this category. Such incidents often involve what Stang Dahl (1994) refers to as 'series of acts of force'. 2 This category of acts challenges the idea of unwanted touching as being minor events and underlines the importance of looking at the interaction involved in order to understand how unwanted touching comes about in different situations.

Aggressive touching from friends and acquaintances happened in a range of contexts - at parties and after-parties, in cars, outdoors and at home or at a friend's house. Most of the incidents took place in a private space or away from other youths.

I was held hard and not allowed to go home; he touched me.

[I] was taken advantage of the first time I drank alcohol, by the boy next door. He locked us in a restroom.

The boy was stalking me the whole evening; we were sitting with others, but he still tried to touch my breasts and kiss me, even after I pushed him away.

He was suddenly on top of me [and] pressed me down against the floor. I could hardly move; he made me touch him and masturbate him against my will. He knew it was against my will.

Some of the descriptions illustrate how unwanted touching can shift from being explorative to becoming aggressive, thus illustrating the point about the fluidity of the phenomenon described above. The quote below is an apt illustration:

We sat next to each other, relaxing. He liked me and wanted to touch me. He tried, but he took no for an answer. Eventually.

The word 'eventually' in the quote above suggests that the boy ignored her first 'no' or rejection. This situation had thus seemingly started out as a form of invitation but then developed into a more insistent and aggressive approach. These situations 
may be understood as being linked to the same heterosexual 'hooking-up' logic as explorative touching, which underlines the boy's responsibility to make the first move. The difference in this case is that he ignores her initial rejection and continues to touch her, which also means that these situations are different from the 'competing definitions of the situation' scenarios that Kavanaugh (2013) describes. Like attacks on drunk and sleeping girls, these incidents could be interpreted as displays of male entitlement. The same would be the case for other incidents of aggressive touching that take the form of 'blitz' attacks - sudden and violent and seemingly random.

Very few descriptions of unwanted sexual touching from boyfriends appeared in the material; among the ten descriptions, all could be labelled as aggressive touching. Four descriptions were related to situations where the girl was young - 13 or 14 years old. In two of these cases, the boy was equally young, while in the other two cases, the boy was three to four years older. A commonality seems to be that he wanted her to engage in a sexual activity that she felt she was not ready for - either because of her age or because the relationship was very new. He either applied pressure or force or took advantage of her being younger and more vulnerable.

My boyfriend touched my breasts and down there; I didn't want to, but I didn't dare say anything.

Girl 13, boy 17

He forced me to masturbate him, and he touched my upper body. He locked me in because he wanted to finger me. This happened twice, but I kicked him in the groin. Everything happened at practice: either in the boys' locker room or in the back room.

Girl 13, boy 16

He absolutely wanted to do something sexual with me. I didn't want to, because it was too early [in the relationship]. We'd been together a week. It ended with me masturbating him, and then he was angry because I didn't want to do anything more.

Both 14

The other incidents involved sexual touching after the girl had explicitly said no, or she woke up being touched.

He touched me even if I said no.

I woke up because my boyfriend was fingering me. Earlier that evening, I'd made it clear that I didn't want to have sex.

Given the few descriptions, we cannot draw clear conclusions from this material. Still, it seems reasonable to hypothesise that unwanted sexual touching within teenage romantic relationships is primarily a risk for young girls who, because of their age, are less experienced sexually than their partners. Such touching is also indicative 


\section{Kari Stefansen}

of how very young boys may act out a form of male entitlement to sex in romantic relationships. In some cases, the touching is also facilitated by acts of force.

\section{Situations involving strangers}

In the descriptions involving strangers, performative touching as described above was not common. Descriptions of unwanted sexual touching in public or semi-public spaces were mentioned, but they were of a different quality. These descriptions portrayed behaviour that was unlikely to produce acclaim from peers or any other audience, because it deviated too much from the standard script for sexual or romantic advances. They had a bizarre quality and had associations with something out of control akin to episodic madness, sometimes related to intoxication, as illustrated below:

I was at a party; someone came up to me and started to talk. Then he took his clothes off. I ran away terrified and said I had a boyfriend. Then he put a stranglehold on my boyfriend. I and a few others managed to pull him away, and I cried for a long time. We went home right after.

I was sitting on a bench; someone I didn't know moved closer and closer to me without me noticing before he started to touch me. I ran away, and he didn't follow.

He pursued me on my way home from practice and exposed himself twice on the road, and he wanted me to touch him. He touched my breasts and put his finger against my bum. He was reported to the police and was given a fine.

Public touching from strangers also happens in covert ways: for instance, in a crowd of people. In these situations, the others present are not positioned as an audience, as in performative touching, but represent a facilitating context, as shown in the following quotes:

It happened on the bus when it was crowded, and it happened naturally that people bumped into each other. After a while I realised that someone had touched my bum and that it wasn't an accident. I tried to move but couldn't get away. I heard later that it was a group that did this systematically.

We were at a concert, my friends and I. When we were standing in the middle of a crowd of people, I felt a hand stroking me from the front and back between my legs. I turned around, and a boy was standing there grinning. I asked him, 'What the fuck are you doing?' I slapped him and walked away.

He started to touch me when I was standing in the streetcar. I screamed and hit him, and he left. 
[He was] just someone who passed me and put his hand between my legs and tried to touch me, but he walked away so that no one could see what he'd done. I felt nauseous and lost, but I didn't do anything about it.

These forms of public touching do not seem to fit the three initial categories of acts involving friends/acquaintances and boyfriends (performative, explorative and aggressive touching). What they have in common is a total break with the social contract of the situation. They are acts that are 'out of place' and therefore disturbing. The first cluster of acts are clearly deviant and outside the normal. The second cluster is associated with immature forms of rule-breaking behaviour, sexualised pranks or stunts with a sexual content. The notion of 'opportunistic predation' developed by Kavanaugh (2013) is perhaps relevant; they could also be labelled as 'random predation' - the affected girls just happened to be there when the impulse to reach out occurred. In this sense, these acts could be thought of as a gendered parallel to what has been called meaningless or 'blind' violence between men, typically in urban areas and late at night and committed for no apparent reason. Following this idea, we could consider these random acts of unwanted touching as a form of 'blind sexual violence': blind in the sense that they neither follow from any prior personal interaction nor are sparked by any social energy or shared definition of the situation.

In addition to these disturbing and apparently random forms of unwanted touching, girls described unwanted touching from strangers at pubs, clubs, parties and other social-drinking arenas. These incidents resemble the incidents involving friends and acquaintances from the same social contexts. They seem to be related to displaying or living up to a sexually charged party atmosphere, which I infer from the difference in reactions to the same type of in-passing sexualised touching within other types of public arenas, described above. In these situations, the girls reacted by screaming, slapping the offender or by feeling nauseous and lost. In comparison, girls could describe inpassing sexual touching at nightclubs and parties as 'a minor thing', 'nothing severe' and 'not serious'. One possibility is that in these situations, the girls did not want to be touched - in the sense that they did not want to be touched by a specific person - but they also acknowledged that the touching had been spurred on by the general atmosphere and that they added to the general sexual vibe of the situation. Hence, the girls could think of these acts as being objectifying in a positive sense.

It was nothing severe - just a club where boys are a bit eager to touch you.

Boys who are the grabby type at clubs, but nothing serious.

Me and my friends were out on the town, dancing. We [often] dance with others we meet and with each other, and some of the boys and men out there are a bit creepy. [The girl used a Norwegian term for men who touch women in a sexual way without their permission: 'klåfingret'.] 


\section{Kari Stefansen}

In his discussion of the literature on the affective dimensions of nightlife, Tutenges (2012, p. 133) points to how such environments 'may be understood as force fields of emotional energy where individuals can be assisted in the difficult task of transgressing the confines of their ordinary selves and becoming more wild and adventurous' (see also Pedersen, Tutenges, \& Sandberg, 2017; Tutenges, 2013). Drawing on Williams (2008), Fileborn (2016, p. 18) contends that 'the un-known nature of night-time spaces ... give[s] rise to the possibility of experiences that are not available in day-time spaces'; according to Williams (2008, p. 519), 'the potential for "non-normalised" behaviours' are therefore present. Fileborn (2016, p. 36) uses the word 'downplaying' for situations where her interviewees talked about incidents of unwanted sexual attention in such situations as being 'harmless', or when they described themselves as being able to handle the unwanted attention. An alternative interpretation - one that does not exclude Fileborn's interpretation - is that these incidents are at the same time part of what makes spaces sexually laden and dangerous in the positive sense. Rather than treating them as serious transgressions that are downplayed, this perspective highlights how the situations are open to alternative interpretations and hence may be experienced as being less intrusive. The premise is that incidents that are linked to the underlying social contract - even if they represent transgressions - are less disturbing than incidents that more clearly are out of sync with this contract.

At the same time, a form of ambivalence exists related to incidents like those portrayed above. They are not very severe incidents, and they seem to be part of the normal flow of interaction or meaning - but the line between acknowledging/positive objectifying touching and degrading/objectifying touching is very fine. In some situations, this type of touching is more problematic and is felt as a clear invasion of one's private space.

[I] was out dancing at a club when a boy came over to dance. After a while, he put his hands on my boobs. I removed his hands and told him off. He was offended and left.

I was at a club when this guy came over and put his arms around me from behind outside of my sweater and touched my boobs. He was thrown out of the club later.

It was at a party. Everybody was really drunk. [I'd] flirted a little but didn't mean anything serious. He started to be way too intense and touched me uncomfortably. A male friend 'saved' me.

The last quote above also illustrates how a situation involving a stranger can shift from one mode to the other - from an explorative interaction to the crossing of boundaries and changing of the atmosphere. 


\section{Conclusion}

Mindful that my analysis is based on empirical material that is limited in terms of depth and context, I have described and conceptualised distinct forms of unwanted touching that are distinguishable by their socio-spatial dynamics. As Fileborn (2016, p. 5) has noted, I have also explored experiences that "sit "on the margins" of our current understanding of sexual violence' - the implication being that unwanted sexual attention, and touching, only sometimes fall within our concept of sexual violence. In the following, I discuss how we can meaningfully differentiate between the two situations: those that fall within the concept of sexual violence that has guided my analysis, and those that do not. To that end, I apply Cahill's sexual-ethics framework $(2014,2016)$. Her idea, as outlined in the introduction to this chapter, is that for an act to qualify as sexual violence, it must represent a nullification of the victim's agency or interest in the situation. This means that situations that grant the victim some form of leeway or agency fall short of sexual violence. If the victim's agency nevertheless is compromised, then such situations are unethical and often problematic (and in some cases traumatic), but they do not constitute sexual violence.

How can we then understand the different forms of unwanted sexual touching that girls experience if we read them through this particular lens? Two of the situations seem rather clear-cut in terms of the leeway allowed for the affected girl: unwanted touching from friends and acquaintances at school (performative touching) and public unwanted touching from strangers in non-sexualised spaces (random predation). In these situations, the sexual act is meant for the thrill or amusement of the collective of spectators or the individual assailant; it is not an act that follows from a prior or ongoing interaction between the girl and the assailant. The level of reciprocity in the interaction is low or non-existent. The act is unrelated to her interest in the situation: what she says or does has no implication in the situation. Her presence is that of an object; it is not a social presence. The act therefore represents sexual violence.

The same is the case for the aggressive sexual touching that happens both within teenage romantic relationships and other social relations. These situations portray nullification of her agency: in a sense, he has performed the sexual or sexualised acts on her (Hansen, 2018). Hence, her interest in the situation of not engaging with him at all or in a specific way is not allowed to influence his acts. In these situations, acts of unwanted sexual touching 'fixate a gendered and embodied experience' (Gottzén, 2018, p. 116) on the part of the victim and hence represent a complete closure of the potentiality for rejection and control that the idea of gender freedom (Stang Dahl, 1994) presupposes.

For the three remaining situations - explorative touching from friends/acquaintances that signals romantic or sexual interest, and in-passing touching by both friends/acquaintances, and strangers in party and club settings - the picture is less clear-cut. These situations are linked to more or less sexualised spaces, i.e. spaces with an affective atmosphere that suggests that they are places for sexual advances and possibly contact. For the first type of touching (the making-a-pass type of touching), her reaction and his ensuing response of retreat - the instant backing off - demonstrate that she has agency in the situation and that it is put to productive 


\section{2}

Kari Stefansen

use: he quickly changes his behaviour. Hence, such situations fall short of the definition of sexual violence as the eradication of self-determination or loss of control relating to sex and sexual encounters and relations. Because such incidents happen in public or semi-public places, they could also be interpreted as having a performative dimension. What separates these incidents from clear cases of performative touching is, as described above, the leeway for her agency or will.

For the latter types of unwanted touching - the types that happen on the dance floor, or in other spaces within drinking venues or parties - the question of the scope of the affected girl's interest or will is more complicated. If her interest or will is related to becoming absorbed in the sexualised atmosphere, then his transgression in a sense is in line with her interest. Her reaction - as well as her classification of the incident as unwanted sexual touching - indicates that this is not the whole story; that his actions do not totally align with her interest but are off-balance or badly timed. I take a cue in this case from Heinskou (2010), who refers to discomfort and unease in sexual or sexualised situations as being related to shifts in temporality: 'the rhythm of the social relation has perhaps jumped a step or a heartbeat, and this can be experienced as a physical form of discomfort' (p. 141). Hence, discomfort may relate not so much to the sexualised act itself but to a lack of synchronisation.

Demant and Heinskou (2011) offer an interesting perspective on transgressions in sexualised party settings. They argue that in order to understand sexual assault among young people, the standard risk perspective should be combined with a perspective on chance: 'analytically, it is suggested that young men and women go to parties and drink in an attempt to take a chance, but the chance, in some cases, backfires' (p. 398; italics in the original). This interpretation is related to the fact that parties also are gendered contexts, with social norms that affect young girls' and boys' sexual expressions and ability to resist sexual advances. Because the 'backfiring' in this case only represents a partial break of the flow of meaning in the situation - i.e. to experience what Demant and Heinskou (2011), drawing on Vance (1984), refer to as the 'pleasures of the dangers' of drinking and partying in my interpretation, the act rests within the realm of the unethical but does not by default cross the border into sexual violence. The premise is that situations of asynchronicity in interests are different from situations totally dominated by the interest of one party in the interaction. As described earlier, in-passing touching in party contexts can also represent cases of opportunistic predation. In these situations the girl's will is undermined in a different way - the touching more clearly demonstrates the domination of the boy's will over hers; the danger involved in touching a more or less random person adds to his thrill only, not hers.

What further complicates the understanding of unwanted sexual touching is the way in which acts that remain outside the boundary of sexual violence work on the cultural or symbolic level, what Fileborn $(2016$, p. 6) calls the 'background' experiences of sexualised violence. Cahill (2001) makes a similar point. She writes about how her knowledge of girls' vulnerability to sexual violence and of her female friends' experiences combine to affect her own self-understanding as being 'rapeable' and therefore as someone who must be careful: 'the possibility of rape shapes the space I inhabit' (p. 1). 
My point is that the minor transgressions that do not cross the boundary of sexual violence also feed into the 'phenomenology of fear' among girls and women that Cahill (2001, p. 143) describes. In this sense, unethical sexual acts are far from innocent or 'minor'. As Stefansen et al. (2014) have commented, such incidents may work as a form of implied gendered violence (cf. Sheffield, 1987) that affects girls in general. Cornell's $(1995,2007)$ notion of the 'imaginary domain' is helpful to explain this point. The imaginary domain is the psychic space that allows people the freedom to think about who they want to be as sexuate and sexual beings. The micro-transgressions that girls encounter on a regular basis shrink this space for girls and women in general. They work as constant reminders that girls must take into account that their right to bodily integrity is less protected than it is for boys. Such acts may therefore spur girls to adjust what their interest in a situation can be: to the possibility of sexual assault. Some girls, for example, may refrain from engaging in the sexualised energy of party and night-time spaces, which not only deprives them of the possibility for positive transgressions - of letting go of their controlled, everyday selves (Tutenges, 2012) - but may also leave them more vulnerable to experiencing sexual violence. Those absorbed in the party vibe may feel or treat micro-transgressions on the dance floor or at the bar as minor; for those who are not, the same acts are more likely to be experienced as a violent attack that demands a response, such as anger, disgust, shame or fear. Hence, what is intended as protective or preventive behaviour may paradoxically become a risk factor.

\section{Acknowledgements}

This chapter was written as part the Domestic Violence Research Programme at Oslo Metropolitan University, funded by the Norwegian Ministry of Justice and Public Security. The author would like to extend a warm thanks to Marie Heinskou, MayLen Skilbrei and Ingrid Smette for their valuable comments on earlier versions of the chapter.

\section{Notes}

1 As Patosalmi (2009) has discussed, Cornell's (2007) theory of the imaginary domain is complex and is founded on ideas of subjectivity and the person from psychoanalytic thinking. In this chapter, I use the notion of the imaginary domain as a metaphor in order to draw our attention to the collective or systemic aspect of sexual violence.

2 In Norwegian: 'Serier av tvangshandlinger'.

\section{References}

Bakken, A. (2017). Ungdata: Nasjonale resultater 2017. Oslo: NOVA.

Bjørnholt, M., \& Helseth, H. (2019). 'Jeg ville jo bare si nei' - Seksuell vold i parforhold. In K. Skjørten, E. Bakketeig, M. Bjørnholt, \& S. Mossige (Eds.), pp. 85-103. Vold i ncere relasjoner: Forståelser, konsekvenser og tiltak. Oslo: Universitetsforlaget.

Cahill, A. J. (2001). Rethinking rape. Ithaca, NY: Cornell University Press. 


\section{Kari Stefansen}

Cahill, A. J. (2014). Recognition, desire, and unjust sex. Hypatia, 29(2), 303-319.

Cahill, A. J. (2016). Unjust sex vs. rape. Hypatia, 31(4), 746-761.

Collins, R. (2009). Violence: A micro-sociological theory. Princeton, NJ: Princeton University Press.

Cornell, D. (1995). The imaginary domain: Abortion, pornography and sexual harassment. New York: Routledge.

Cornell, D. (2007). The shadow of heterosexuality. Hypatia, 22(1), 229-242.

Demant, J., \& Heinskou, M. B. (2011). Taking a chance: Sex, alcohol and acquaintance rape. Young, 19(4), 397-415.

Fileborn, B. (2016). Reclaiming the night-time economy: Unwanted sexual attention in pubs and clubs. London: Palgrave Macmillan.

Gillander Gådin, K., \& Stein, N. (2017). Do schools normalise sexual harassment? An analysis of a legal case regarding sexual harassment in a Swedish high school. Gender and Education, 1-18. doi: 10.1080/09540253.2017.1396292

Gottzén, L. (2018). Geographies of anger and fear: Exploring the affective atmospheres of men's 'domestic' violence. In M. Livholts \& L. Bryant (Eds.), Social work in a glocalised world (pp. 106-118). London: Routledge.

Graham, K., Bernards, S., Abbey, A., Dumas, T. M., \& Wells, S. (2017). When women do not want it: Young female bargoers' experiences with and responses to sexual harassment in social drinking contexts. Violence against Women, 23(12), 1419-1441.

Hansen, M. L. J. (2018). Vilje og motvilje: Fortellinger bak ikke-anmeldte voldtekter. (MA thesis in criminology). Oslo: University of Oslo.

Heinskou, M. B. (2010). En kompleks affare: Anmeldte voldtogter i Danmark. $\mathrm{PhD}$ dissertation. Copenhagen: Copenhagen University.

Kahn, A. S. (2004). 2003 Carolyn Sherif award address: What college women do and do not experience as rape. Psychology of Women Quarterly, 28(1), 9-15.

Kahn, A. S., Jackson, J., Kully, C., Badger, K., \& Halvorsen, J. (2003). Calling it rape: Differences in experiences of women who do or do not label their sexual assault as rape. Psychology of Women Quarterly, 27(3), 233-242.

Kavanaugh, P. R. (2013). The continuum of sexual violence: Women's accounts of victimization in urban nightlife. Feminist Criminology, 8(1), 20-39.

Kelly, L. (1988). Surviving sexual violence. Cambridge, UK: Polity Press.

Khan, S. R., Hirsch, J. S., Wambold, A., \& Mellins, C. A. (2018). 'I didn't want to be "that girl"': The social risks of labeling, telling, and reporting sexual assault. Sociological Science, $5,432-460$.

Krange, O., \& Pedersen, W. (1999). Å angre på sex. Sosiologisk tidsskrift, 7(1), 45-70.

Lahelma, E. (2002). Gendered conflicts in secondary school: Fun or enactment of power? Gender and Education, 14(3), 295-306.

LeMaire, K. L., Oswald, D. L., \& Russell, B. L. (2016). Labeling sexual victimization experiences: The role of sexism, rape myth acceptance, and tolerance for sexual harassment. Violence and Victims, 31(2), 332.

McGlynn, C., \& Munro, V. E. (Eds.). (2010). Rethinking rape law: International and comparative perspectives. London: Routledge.

Megarry, J. (2014). Online incivility or sexual harassment? Conceptualising women's experiences in the digital age. Women's Studies International Forum, 47(Part A), 46-55.

Mossige, S., \& Stefansen, K. (2007). Vold og overgrep mot barn og unge: En selvrapporteringsstudie blant avgangselever $i$ videregående skole. Oslo: NOVA. 
Mossige, S., \& Stefansen, K. (2016). Vold og overgrep mot barn og unge: Omfang og utviklingstrekk 2007-2015. Oslo: NOVA.

Munro, V. E. (2010). From consent to coercion: Evaluating international and domestic frameworks for the criminalization of rape. In C. McGlynn \& V. E. Munro (Eds.), Rethinking rape law (pp. 17-29). Oxfordshire, UK: Routledge.

Patosalmi, M. (2009). Bodily integrity and conceptions of subjectivity. Hypatia, 24(2), 125-141.

Pedersen, W., Tutenges, S., \& Sandberg, S. (2017). The pleasures of drunken one-night stands: Assemblage theory and narrative environments. International Journal of Drug Policy, 49, 160-167.

Robinson, K. H. (2005). Reinforcing hegemonic masculinities through sexual harassment: Issues of identity, power and popularity in secondary schools. Gender and Education, 17 (1), 19-37.

Sheffield, C. J. (1987). Sexual terrorism: The control of women. In B. B. Hess \& M. M. Ferree (Eds.), Analyzing gender: A handbook of social science research (pp. 171-189). Newbury Park, CA: Sage.

Skilbrei, M.-L., \& Stefansen, K. (2018). Seksuell vold: En samfunnsvitenskapelig innføring. Oslo: Cappelen Damm Akademisk.

Smart, C. (1995). Law, crime and sexuality: Essays in feminism. London: Sage.

Stang Dahl, T. (1994). Pene piker haiker ikke. Oslo: Universitetsforlaget.

Stefansen, K., Överlien, C., \& Frøyland, L. (in preparation). Exploring gendered aspects of incapacitated sexual assaults among teenagers.

Stefansen, K., \& Smette, I. (2006). Det var ikke en voldtekt, mer et overgrep: Kvinners fortolkninger av seksuelle overgrepserfaringer. Tidsskrift for samfunnsforskning, 47(1), 33-56.

Stefansen, K., Smette, I., \& Bossy, D. (2014). Angrep mot kjønnsfriheten: Unge jenters erfaringer med uønsket beføling. Tidsskrift for kjønnsforskning, 38(1), 3-19.

Thompson, L. (2018). 'I can be your Tinder nightmare': Harassment and misogyny in the online sexual marketplace. Feminism \& Psychology, 28(1), 69-89.

Tinkler, J. E., Becker, S., \& Clayton, K. A. (2018). 'Kind of natural, kind of wrong': Young people's beliefs about the morality, legality, and normalcy of sexual aggression in public drinking settings. Law \& Social Inquiry, 43(1), 28-57.

Tutenges, S. (2012). Nightlife tourism: A mixed methods study of young tourists at an international nightlife resort. Tourist Studies, 12(2), 131-150.

Tutenges, S. (2013). Stirring up effervescence: An ethnographic study of youth at a nightlife resort. Leisure Studies, 32(3), 233-248.

Vance, C. S. (1984). Pleasure and danger: Toward a politics of sexuality. In C. S. Vance (Ed.), Pleasure and danger: Exploring female sexuality (pp. 1-27). Boston, London, Melbourne, and Henley, UK: Routledge \& Kegan Paul.

Vera-Gray, F. (2016). Men's stranger intrusions: Rethinking street harassment. Women's Studies International Forum, 58(September-October), 9-17.

Williams, R. (2008). Night spaces: Darkness, deterritorialization, and social control. Space and Culture, 11(4), 514-532. 